\title{
The role of digital marketing in political campaigns
}

\section{Jeff Chester}

Center for Digital Democracy, Washington, DC, United States of America

\section{Kathryn C. Montgomery}

School of Communication, American University, Washington, DC, United States of America

Published on 30 Dec 2017 | DOI: 10.14763/2017.4.773

\begin{abstract}
Computational politics-the application of digital targeted-marketing technologies to election campaigns in the US and elsewhere-are now raising the same concerns for democratic discourse and governance that they have long raised for consumer privacy and welfare in the commercial marketplace. This paper examines the digital strategies and technologies of today's political operations, explaining how they were employed during the most recent US election cycle, and exploring the implications of their continued use in the civic context. The paper concludes with a discussion of recent policy proposals designed to increase transparency and accountability in digital politics.
\end{abstract}

Keywords: Elections, Advertising, Privacy, Analytics, Profiling

\section{Article information}

Received: 01 Nov 2017 Reviewed: 20 Dec 2017 Published: 30 Dec 2017

Licence: Creative Commons Attribution 3.0 Germany

Competing interests: The author has declared that no competing interests exist that have influenced the text.

URL: http://policyreview.info/articles/analysis/role-digital-marketing-political-campaigns

Citation: Chester, J. \& Montgomery, K. C. (2017). The role of digital marketing in political campaigns. Internet Policy Review, 6(4). https://doi.org/10.14763/2017.4.773

This paper is part of Political micro-targeting, a special issue of Internet Policy Review guestedited by Balázs Bodó, Natali Helberger, and Claes H. de Vreese.

\section{INTRODUCTION}

Political campaigns in the United States have employed digital technologies for more than a decade, developing increasingly sophisticated tools and techniques during each election cycle, as "computational politics" have become standard operating procedure (Tufecki, 2014; Kreiss, 2016). However, the most recent election marked a critical turning point, as candidates, political action committees, and other interest groups were able to take advantage of significant 
breakthroughs in data-driven marketing techniques, such as cross-device targeting, developed since the previous presidential election ("Bernie Sanders", 2016; Edelman Digital, 2016). Electoral politics has now become fully integrated into a growing, global commercial digital media and marketing ecosystem that has already transformed how corporations market their products and influence consumers (Chahal, 2013; LiveRamp, 2015; Rubinstein, 2014; Schuster, 2015).The strategies, technologies, and tools of digital political marketing are more complex and far-reaching than anything we have seen before, with further innovations already underway (WARC, 2017). But because most commercial and political digital operations take place below the radar, they are not fully understood by the public. 1

In the following pages, we briefly describe the growth and maturity of digital marketing, highlighting its basic features, key players, and major practices. We then document how datadriven digital marketing has moved into the centre of American political operations, along with a growing infrastructure of specialised firms, services, technologies and software systems. We identify the prevailing digital strategies, tactics, and techniques of today's political operations, explaining how they were employed during the most recent US election cycle. Finally, we explore the implications of their use for democratic discourse and governance, discussing several recent policy developments aimed at increasing transparency and accountability in digital politics.

Our research for this paper draws from our extensive experience tracking the growth of digital marketing over the past two decades in the United States and abroad, monitoring and analysing key technological developments, major trends, practices and players, and assessing the impact of these systems in areas such as health, financial services, retail, and youth (Chester, 2007; Montgomery, 2007; Montgomery, Chester, \& Kopp, 2017). During the 2016 US presidential election, we monitored commercial digital advertising and data use by candidates, parties and special interest groups across the political spectrum. We collected examples of these ads, along with technical and market impact information from the developers of the applications. We also reviewed trade journals, research reports, and other industry documents, and attended conferences that were focused on digital technologies and politics. In the process, we identified all of the major providers of political digital data targeting applications (e.g., Google, Facebook, data clouds, ad agencies) and analysed all their key materials and case studies related to their 2016 operations. The source for much of this work was our ongoing gathering and analysis of cross-sectional commercial digital marketing practices worldwide.

\section{MARRIAGE OF POLITICS AND COMMERCE}

Since the mid-20 ${ }^{\text {th }}$ century, advertising has been an increasingly powerful and pervasive presence in US political campaigns, as a growing cadre of ad agencies, public relations firms, and consultants perfected the use of opinion polls, focus groups, and psychographics to reach and influence voters through radio, television, direct mail, and other media outlets (A. Jamieson, 2016; K. H. Jamieson, 1996; Sabato, 1981). With the rise of the internet, campaign operatives began to harness digital technologies and tools to mobilize voter turnout, engage young people, raise money, and support grassroots ground operations (Karpf, 2016; Kreiss, 2016; Tufecki, 2014). Both major political parties in the United States developed large, sophisticated data and digital operations (Kreiss, 2016).

Many of the digital strategies, tools, and techniques employed in the 2016 election were initially developed, deployed, tested, and refined by the commercial sector (Tufecki, 2014). Since its 
origins in the mid-1990s, digital marketing has operated with a core business model that relies on continuous data collection and monitoring of individual online behaviour patterns (Montgomery, 2011). This system emerged in the United States amid a political culture of minimal government interference, and within a prevailing laissez-faire ethos regarding the internet and new technologies (Barlow, 1996). In the earliest days of the "dot-com boom", a strong political alliance was forged between the digital media companies and their partners in the advertising and media business, enabling the nascent industry to effectively ward off any attempts to restrain its business operations through privacy regulation or other public policies (Solon \& Siddiqui, 2017). As a consequence, the advertising industry played a central role in shaping the operations of platforms and applications in the digital media ecosystem. Digital marketing is now well established and thriving, with expenditures reaching nearly $\$ 72.5 \mathrm{bn}$ in 2016 for the US alone, and worldwide spending predicted to reach more than $\$ 223 \mathrm{bn}$ this year (eMarketer, 2017; IAB, n.d.-d).

Ongoing innovations over the years have increased the capacity of data and digital marketing applications. Data collection, analysis, and targeting were further woven into the daily lives of consumers with the rise of social media platforms and mobile devices. Because of the unique role that they play in users' lives, these platforms are able to sweep up enormous amounts of information, including not only what users post about themselves, but also what is collected from them throughout their daily activities (Smith, 2014). A growing arsenal of software and analytic tools has enhanced the ability of digital media companies and their advertisers to glean valuable insights from the oceans of data they generate (Smith, 2014). Predictive analytics introduced an expanded set of tools for scoring, rating, and categorising individuals, based on an increasingly granular set of behavioural, demographic, and psychographic data ("What is Predictive Intelligence", 2017). US digital marketers have helped popularise and spur the successful adoption of digital advertising platforms and applications in nearly every geographical location with an internet connection or a link to a mobile device (IAB, n.d.-c). Google, Facebook, and other major players in the digital marketing industry have also developed a global research infrastructure to allow them, and especially their major advertising clients, to make continuous improvements in reaching and influencing the public, and to measure with increasing accuracy the success of their efforts (Facebook IQ, n.d.-a). These developments have created what some observers have called the "surveillance economy" (Singer, 2012).

\section{THE GROWTH OF DATA-DRIVEN POLITICAL MARKETING}

Though political campaigns have employed micro-targeting techniques-which use an array of personalised and other data sets and marketing applications to influence the actions of individuals-during the last several election cycles, recent technological innovations and industry advances have created a much more robust system than what was in place in 2012 (IAB, n.d.-b; Rubinstein, 2014). For years, political campaigns have been able to combine public voter files with commercial information from data brokers, to develop detailed and comprehensive dossiers on American voters (Rubinstein, 2014). With recent advances in the advertising technology and data industries, they can now take advantage of a growing infrastructure of specialty firms offering more extensive resources for data mining and targeting voters. Among the new entities are data marketing clouds. Developed by well-known companies such as Adobe, Oracle, Salesforce, Nielsen, and IBM, these clouds sell political data along with an exhaustive amount of detailed consumer information for each potential target, including, for 
example, credit card use, personal interests, consumption patterns, and TV viewing patterns (Salesforce DMP, 2017).

Some of these massive cloud services also operate what has become a new and essential component for contemporary digital targeting-the data management platform (DMP) (Chavez, 2017). DMPs provide marketers with "centralized control of all of their audience and campaign data" (BlueKai, 2011). They do this by collecting and analysing data about individuals from a wide variety of online and offline sources, including first-party data from a customer's own record, such as the use of a supermarket loyalty card, or their activities captured on a website, mobile phone, or wearable device; second-party data, information collected about a person by another company, such as an online publisher, and sold to others; and third-party data drawn from thousands of sources, comprising demographic, financial, and other data-broker information, including race, ethnicity, and presence of children (O'Hara, 2016). All of this information can be matched to create highly granular "target audience segments" and to identify and "activate" individuals "across third party ad networks and exchanges". DMPs are quickly becoming a critical tool for political campaigns (Bennett, 2016; Kaye, 2016, July; Regan, J., 2016).

Facebook and Google now play a central role in political operations, offering a full spectrum of commercial digital marketing tools and techniques, along with specialied ad "products" designed for political use (Bond, 2017). Not surprisingly, these companies have also made generating revenues from political campaigns an important "vertical" category within their ad business (Facebook, n.d.-d; Facebook IQ, n.d.-b; Stanford, 2016). Facebook's role in the 2016 election was particularly important. With users required to give their real names when they sign up as members, Facebook has created a powerful "identity-based" targeting paradigm, enabling political campaigns to access its more than 162 million US users and to target them individually by age, gender, congressional district, and interests (Facebook, n.d.-b).Its online guide for political campaign marketing urges political campaigns to use all the social media platform tools it makes available to advertisers-including through Instagram and other properties-in order to track individuals, capture their data through various "lead-generation" tactics, and target them by uploading voter files and other data (Facebook, n.d.-a-c-f). The company also employs teams of internal staff aligned with each of the major political parties to provide technical assistance and other services to candidates and their campaigns (Chester, 2017; Kreiss \& Mcgregor, 2017). Google heavily promoted the use of YouTube, as well as its other digital marketing assets, during the 2016 US election, reaching out to both major political parties (YouTube, 2017).

The growth and increasing sophistication of the digital marketplace has enhanced the capacities of political campaigns to identify, reach, and interact with individual voters. Below we identify seven key techniques that are emblematic of this new digital political marketing system, providing brief illustrations of how they were employed during the 2016 election.

\section{CROSS-DEVICE TARGETING}

Getting a complete picture of a person's persistent "identity" through an "identity-graph" has become a key strategy for successfully reaching consumers across their "omnichannel" experience (use of mobile, TV, streaming devices, etc.) (Winterberry Group, 2016). "Crossdevice recognition" allows marketers to determine if the same person who is on a social network is also using a personal computer and later watching video on a mobile phone. Through data "onboarding," a customer record that may contain a physical and email address is linked through various matching processes, associating it with what is believed to be that individual's 
online identification-cookies, IP addresses, and other persistent identifiers (Levine, 2016). Cross-device targeting is now a standard procedure for political initiatives and other campaigns. Voter files are uploaded into the onboarding process, enabling the campaigns to find their targets on mobile devices and at specific times when they may be more receptive to a message (Kaye, 2016, April; L2, n.d.-b). Such granularity of information also enables a more tailored advertisement-so-called "dynamic creative"-which can be changed over time to "deliver very specific messaging” to individuals (Schuster, 2015). Leading cross-device marketing company Drawbridge offered a suite of election services in 2016 that provided campaigns a number of ways to impact voters, including through "Voter-Centric Cross Device Storytelling", "Political Influencer Identification”, and via "Real-Time Voter Attribution Measurement" (Drawbridge, n.d.).

\section{PROGRAMMATIC ADVERTISING}

Programmatic advertising refers to new automated forms of ad buying and placement on digital media using computer programmes and algorithmic processes to find and target a customer wherever she goes. The process can also involve real-time "auctions" that occur in milliseconds in order to "show an ad to a specific customer, in a specific context" (Allen, 2016). The use of programmatic advertising was one of the major changes in political campaign digital operations between 2012 and 2016-"the first time in American History", according to one ad company, "that such precise targeting has ever been made available at such great scale" (Briscoe, 2017; Kaye, 2015). Programmatic advertising has itself grown in its capabilities to reach individuals, taking advantage of new sources of data to reach them on all of their devices (Regan, T., 2016). In 2016, for example, global ad giant WPP's Xaxis system-"the world's largest programmatic and technology platform"-launched "Xaxis Politics". Capable of "reaching US voters across all digital channels". the system is said to "segment audiences by hundreds of hot button issues as well as by party affiliation", including via "real-time campaigns tied to specific real-world events" (Xaxis, 2015). Candidates were able to use the services of a growing list of companies, including Google, Rubicon, AOL, PubMatic, Appnexus and Criteo, that offered programmatic advertising platforms ("Political Campaigns", 2016; Yatrakis, 2016).

\section{LOOKALIKE MODELLING}

The use of big data analytics enables marketers to acquire information about an individual without directly observing behaviour or obtaining consent. They do this by "cloning" their "most valuable customers"in order to identify and target other prospective individuals for marketing purposes (LiveRamp, 2015). For example, Stirista (n.d.), a digital marketing firm that also serves the political world, offers lookalike modelling to identify people who are potential supporters and voters. The company claims it has matched 155 million voters to their "email addresses, online cookies, and social handles", as well as "culture, religion, interests, political positions and hundreds of other data points to create rich, detailed voter profiles". Facebook offers a range of lookalike modelling tools through its "Lookalike Audiences" ad platform. For example, Brad Parscale, the Trump campaign's digital director, used the Lookalike Audiences ad tool to "expand" the number of people the campaign could target (Green \& Issenberg, 2016). Facebook's "Custom Audiences" product, similarly, enables marketers to upload their own data files so they can be matched and then targeted to Facebook users (Facebook, n.d.-e).

\section{GEOLOCATION TARGETING}

Mobile devices continually send signals that enable advertisers (and others) to take advantage of an individual's location-through the phone's GPS (global positioning system), Wi-Fi, and Bluetooth communications. All of this can be done with increasing speed and efficiency. Through a host of new location-targeting technologies, consumers can now be identified and 
targeted wherever they go, while driving a car, pulling into a mall, or shopping in a store (Son, Kim, \& Shmatikov, 2016). A complex and growing infrastructure of geolocation-based datamarketing services has emerged, with specialised mobile data firms, machine-learning technologies, measurement companies, and new technical standards to facilitate on-the-go targeting (Warrington, 2015). The use of mobile geo-targeting techniques played a central role in the 2016 election cycle, with a growing number of specialists offering their services to campaign operatives. For example, L2 (n.d.-a) made its voter file, along with HaystaqDNA modelling data, available for mobile device targeting, offering granular profile data on voters based on their interest in such contested topics as gun laws, gay marriage, voter fraud, and school choice, among others. Conde Nast's Advance Publications' election advertising worked with campaigns to append geo-location, profile data, and buying behaviour "to sculpt a very specific voter profile and target down to few hundred readers in a given geo location" (Ellwanger, 2016).

\section{ONLINE VIDEO ADVERTISING}

Digital video, via mobile and other devices, is perceived as a highly effective way of delivering emotional content on behalf of brands and marketing campaigns (IAB, n.d.-a). There are a variety of online video ad formats that provide both short- and long-form content, and that work well for political and other marketing efforts. Progressive political campaign company Revolution Messaging, which worked for the Sanders campaign, developed what it calls "smart cookies" that it says take video and other ad placement "to the next level, delivering precision and accuracy" (Revolution Messaging, n.d.). Google's YouTube has become a key platform for political ads, with the company claiming that today, voters make their political decisions not in "living rooms" in front of a television but in what it calls "micromoments" as people watch mobile video (DoubleClick, n.d.). According to the company's political ad services research, mobile devices were used in nearly 60 percent of election-related searches during 2016. Content producers (which it calls "Creators") on YouTube were able to seize on these election micromoments to influence the political opinions of potential voters 18-49 ("Letter from the Guest Editors," 2016).

\section{TARGETED TV ADVERTISING}

Television advertising, which remains a linchpin of political campaign strategy, is undergoing a major transformation, as digital technologies and "addressable" set-top boxes have changed cable and broadcast TV into powerful micro-targeting machines capable of delivering the same kinds of granular, personalised advertising messages to individual voters that have become the hallmark of online marketing. Political campaigns are in the forefront of using set-top box "second-to-second viewing data", amplified with other data sources, such as "demographic and cross-platform data from a multitude of sources" via information brokers, to deliver more precise ads (Fourthwall Media, n.d.; Leahey, 2016; NCC Media, n.d.). NCC Media, the US cable TV ad platform owned by Comcast, Cox, and Spectrum, provided campaigns the ability to target potential voters via the integration of its set-top box viewing information with voter and other data from Experian and others (Miller, 2017). Deals between TV data viewing companies and organisations representing both Republican- and Democratic-leaning groups brought the "targeting capabilities of online advertising to TV ad buys...bringing what was once accessible only to large state-wide or national campaigns to smaller, down-ballot candidates", explained Advertising Age (Delgado, 2016).

\section{PSYCHOGRAPHIC, NEUROMARKETING, AND EMOTION-BASED TARGETING}

Psychographics, mood measurement, and emotional testing have been used by advertisers for many decades, and have also been a core strategy in political campaign advertising (Key, 1974; 
Packard, 2007; Schiller, 1975). The digital advertising industry has developed these tools even further, taking advantage of advances in neuroscience, cognitive computing, data analytics, behavioural tracking, and other recent developments (Crupi, 2015). Granular-based messages that trigger a range of emotional and subconscious responses, to better "engage" with individuals and deepen relationships with commercial brands, have become part of the DNA of digital advertising (McEleny, 2016). Facebook (2015), Nielsen, and most leading brands use "neuromarketing" services worldwide, which utilise neuroscience tools to determine the emotional impact of advertising messages. There is a growing field, recently promoted by Google, of "Emotion Analytics" that takes advantage of "new types of data and new tracking methods" to help advertisers "understand the impact of campaigns-and their individual assets-on an emotional level..." (Kelshaw, 2017). Scholars have identified that the use of "psychological targeting" in advertising enables the influencing of large groups of people by "tailoring persuasive appeals to the psychological needs" of the specific audiences (Matz, et al, 2017). Data company Experian Marketing Services for political campaigns offered data that weaved together "demographic, psychographic and attitudinal attributes" to target voters digitally. Experian claims its data enables campaigns to examine a target's "heart and mind" via attributes related to their "political persona" as well as "attitudes, expectations, behaviours, lifestyles, purchase habits and media preferences (Experian, 2011, 2015). One of the most well publicised and controversial players in the 2016 election was Cambridge Analytica (CA), a prominent data analytics and behavioural communications firm that claimed to be a key component in Donald Trump's victorious campaign. The company used a "five-factor personality model" aimed at determining "the personality of every single adult in the United States of America" (Albright, 2016; Kranish, 2016).Known as OCEAN, the model rated individuals based on five key traits: openness, conscientiousness, extroversion, agreeableness, and neuroticism. Drawing from digital data, voter history, and marketing resources supplied by leading companies, including Acxiom, Experian, Nielsen, GOP firm Data Trust, Aristotle, L2, Infogroup, and Facebook, CA was able to develop an "internal database with thousands of data points per person". Its research also identified key segments that were considered "persuadable", and shaped the advertising content placed "across multiple digital channels (with the most effective ads also appearing on television) (Advertising Research Foundation, 2017; Nix, 2016). The strategy was based on developing messages that were tailored to the vulnerabilities of individual voters (Nix, 2016; Schwartz, 2017). CA has become the subject of much scrutiny and debate, and itself has made conflicting claims, with critics raising concerns over its techniques and expressing scepticism about the extent of its impact (Confessore \& Hakim, 2017; Karpf, 2017). However, the company's work was sufficiently convincing to the leading advertising industry research organisation, the Advertising Research Foundation (2017, March), that it honoured the firm with a "Gold" award in 2017 under its "Big Data" category.

\section{DISCUSSION}

The above description provides only a brief overview of the data-driven marketing system that is already widely in use by candidate and issue campaigns in the United States. The increasingly central role of commercial digital marketing in contemporary political campaigns is reshaping modern-day politics in fundamental ways, altering relationships among candidates, parties, voters, and the media. We acknowledge that digital technologies have made important positive contributions to the vibrancy of the political sphere, including greatly expanding sources of news and information, significantly increasing opportunities for citizen participation, and empowering people from diverse backgrounds to form coalitions and influence policy. The same 
tools developed for digital marketing have also helped political campaigns substantially improve voter engagement, enhance their capacities for "small-donor" fundraising, and more efficiently generate turnout (Moonshadow Mobile, n.d.; Owen, 2017). However, many of the techniques we address in this paper raise serious concerns-over privacy, discrimination, manipulation, and lack of transparency.

Several recent controversies over the 2016 election have triggered greater public scrutiny over some of the practices that have become standard operating procedure in the digital media and marketing ecosystem. For example, "fake news" has a direct relationship to programmatic advertising, the automated system of "intelligent" buying and selling of individuals and groups (Weissbrot, 2016). These impersonal algorithmic machines are focused primarily on finding and targeting individual consumers wherever they are, often with little regard for the content where the ads may appear (Maheshwari \& Isaac, 2016). As a consequence, in the middle of the 2016 election, many companies found themselves with ads placed on "sites featuring pornography, pirated content, fake news, videos supporting terrorists, or outlets whose traffic is artificially generated by computer programs", noted the Wall Street Journal (Nicas, 2016; Vranica, 2017). As a major US publisher explained in the trade publication Advertising Age,

\begin{abstract}
Programmatic's golden promise was allowing advertisers to efficiently buy targeted, quality, ad placements at the best price, and publishers to sell available space to the highest bidders.... What was supposed to be a tech-driven quality guarantee became, in some instances, a "race to the bottom" to make as much money as possible across a complex daisy chain of partners. With billions of impressions bought and sold every month, it is impossible to keep track of where ads appear, so "fake news" sites proliferated. Shady publishers can put up new sites every day, so even if an exchange or bidding platform identifies one site as suspect, another can spring up (Clark, 2017).
\end{abstract}

Criticism from news organisations and civil society groups, along with a major backlash by leading global advertisers, led to several initiatives to place safeguards on these practices (McDermott, 2017; Minsker, 2017). For example, in an effort to ensure "brand safety", leading global advertisers and trade associations demanded changes in how Google, Facebook and others conduct their data and advertising technology operations. As a consequence, new measures have been introduced to enable companies to more closely monitor and control where their ads are placed (Association of National Advertisers, 2017; Benes, 2017; IPA, 2017; Johnson, 2017; Liyakasa, 2017; Marshall, 2017; Timmers, 2015).

The Trump campaign relied heavily on Facebook's digital marketing system to identify specific voters who were not supporters of Trump in the first place, and to target them with psychographic messaging designed to discourage them from voting (Green \& Issenberg, 2016). Campaign operatives openly referred to such efforts as "voter suppression" aimed at three targeted groups: "idealistic white liberals, young women and African Americans". The operations used standard Facebook advertising tools, including "custom audiences" and socalled "dark posts"-"nonpublic paid posts shown only to the Facebook users that Trump chose" with personalised negative messages (Green \& Issenberg, 2016). Such tactics also took advantage of commonplace digital practices that target individual consumers based on factors such as race, ethnicity, and socio-economic status (Google, 2017; Martinez, 2016; Nielsen, 2016). Civil rights groups have had some success in getting companies to change their practices. However, for the most part, the digital marketing industry has not been held sufficiently 
accountable for its use of race and ethnicity in data-marketing products, and there is a need for much broader, industry-wide policies.

\section{CONCLUSION}

Contemporary digital marketing practices have raised serious issues about consumer privacy over the years (Schwartz \& Solove, 2011; Solove \& Hartzog, 2014). When applied to the political arena, where political information about individuals is only one of thousands of highly sensitive data points collected and analysed by the modern machinery of data analytics and targeting, the risks are even greater. Yet, in the United States, very little has been done in terms of public policy to provide any significant protections. In contrast to the European Union, where privacy is encoded in law as a fundamental right, privacy regulation in the US is much weaker (Bennett, 1997; Solove \& Hartzog, 2014; U.S. Senate Committee on Commerce, Science, and Transportation, 2013). The US is one of the only developed countries without a general privacy law. As a consequence, except in specific areas, such as children's privacy, consumers in the US enjoy no significant data protection in the commercial marketplace. In the political arena, there is even less protection for US citizens. As legal scholar Ira S. Rubinstein (2014) explains, "the collection, use and transfer of voter data face almost no regulation". The First Amendment plays a crucial role in this regard, allowing the use of political data as a protected form of speech (Persily, 2016).

The political fallout over the how Russian operatives used Facebook, Twitter, and other sites in the 2016 presidential campaign has triggered unprecedented focus on the data and marketing operations of these and other powerful digital media companies. Lawmakers, civil society, and many in the press are calling for new laws and regulations to ensure transparency and accountability for online political ads ("McCain, Klobuchar \& Warner Introduce Legislation", 2017). The U.S. Federal Election Commission, which regulates political advertising, has asked for public comments on whether it should develop new disclosure rules for online ads (Glaser, 2017). In an effort to head-off regulation, both Facebook and Twitter have announced their own internal policy initiatives designed to provide the public with more information, including what organisations or individuals paid for political ads and who the intended targets were. These companies have also promised to establish archives for political advertising, which would be accessible to the public (Falck, 2017; Goldman, 2017; Koltun, 2017). The US online advertising industry trade association is urging Congress not to legislate in this area, but to allow the industry to develop new self-regulatory regimes in order to police itself (IAB, 2017). However, relying on self-regulation is not likely to address the problems raised by these practices and may, in fact, compound them. Industry self-regulatory guidelines are typically written in ways that do not challenge many of the prevailing (and problematic) business practices employed by their own members. Nor do they provide meaningful or effective accountability mechanisms (Center for Digital Democracy, 2013; Gellman \& Dixon, 2011; Hoofnagle, 2005). It remains to be seen what the outcome of the current policy debate over digital politics will be, and whether any meaningful safeguards emerge from it.

While any regulation of political speech must meet the legal challenges posed by the First Amendment, limiting how the mining of commercial data can be used in the first place can serve as a critically important new electoral safeguard. Advocacy groups should call for consumer privacy legislation in the US that would place limits on what data can be gathered by the commercial online advertising industry, and how that information can be used. Americans currently have no way to decide for themselves (such as via an opt-in) whether data collected on 
their finances, health, geo-location, as well as race or ethnicity can be used for digital ad profiling. Certain online advertising practices, such as the use of psychographics and lookalike modelling, also call for rules to ensure they are used fairly.

Without effective interventions, the campaign strategies and practices we have documented in this paper will become increasingly sophisticated in coming elections, most likely with little oversight, transparency, or public accountability. The digital media and marketing industry will continue its research and development efforts, with an intense focus on harnessing the capabilities of new technologies, such as artificial intelligence, virtual reality, and cognitive computing, for advertising purposes. Advertising agencies are already applying some of these advances to the political field (Facebook, 2016; Google, n.d.-a; Havas Cognitive, n.d.). Academic scholars and civil society organisations will need to keep a close watch on all these developments, in order to understand fully how these digital practices operate as a system, and how they are influencing the political process. Only through effective public policies and enforceable best practices can we ensure that digital technology enhances democratic institutions, without undermining their fundamental goals. 


\section{REFERENCES}

Advertising Research Foundation. (2017, March 21). Cambridge Analytica receives top honor in the 2017 ARF David Ogilvy Awards. Retrieved from

http://www.prnewswire.com/news-releases/cambridge-analytica-receives-top-honor-in-the-20 17-arf-david-ogilvy-awards-300426997.html

Advertising Research Foundation. (2017). Cambridge Analytica: Make America number one. Case study. Retrieved from https://thearf.org/2017-arf-david-ogilvy-awards/winners/

Albright, J. (2016, November 11). What's missing from the Trump election equation? Let's start with military-grade psyops. Medium. Retrieved from https://medium.com/@d1gi/whatsmissing-from-the-trump-election-equation-let-s-start-with-military-grade-psyopsfa22090c8c17

Allen, R. (2016, February 8). What is programmatic marketing? Smart Insights. Retrieved from http://www.smartinsights.com/internet-advertising/internet-advertising-targeting/what-is-pro grammatic-marketing/

Association of National Advertisers. (2017, March 24). Statement from ANA CEO on

Suspending Advertising on YouTube. Retrieved from

http://www.ana.net/blogs/show/id/mm-blog-2017-o3-statement-from-ana-ceo

Barlow, J. P. (1996, February 8). A declaration of the independence of cyberspace. Electronic Frontier Foundation. Retrieved from https://www.eff.org/cyberspace-independence

Benes, R. (2017, August 29). Ad buyers blast Facebook Audience Network for placing ads on Breitbart," Digiday. Retrieved from https://digiday.com/marketing/ad-buyers-blast-facebookaudience-network-placing-ads-breitbart/

Bennett, C. J. (1997). Convergence revisited: Toward a global policy for the protection of personal data? In P. Agre \& M. Rotenberg (Eds.), Technology and privacy: the new landscape (pp. 99-124). Cambridge, MA: MIT Press.

Bennett, C. J. (2016). Voter databases, micro-targeting, and data protection law: Can political parties campaign in Europe as they do in North America? International Data Privacy Law, 6(4), 261-275. doi:10.1093/idpl/ipw021 Retrieved from https://papers.ssrn.com/sol3/papers.cfm?abstract_id=2776299

Bernie Sanders: 2016 presidential campaign. (2016). Facebook Business. Retrieved from https://www.facebook.com/business/success/bernie-sanders

BlueKai. (2011). Whitepaper: Data management platforms demystified. Retrieved from http://www.bluekai.com/files/DMP_Demystified_Whitepaper_BlueKai.pdf

Bond, S. (2017, March 14). Google and Facebook build digital ad duopoly. Financial Times. Retrieved from https://www.ft.com/content/30c81d12-o8c8-11e7-97d1-5e720a26771b

Briscoe, G. (2017, March 7). How political digital advertising lessons of 2016 applies to 2017. Centro. Retrieved from https://www.centro.net/blog/political-digital-advertising-lessons2016-applies-2017/

Center for Digital Democracy. (2013, May 29). U.S. online data trade groups spin digital fairy 
tale to USTR about US consumer privacy prowess-CDD says privacy out of bounds in TTIP. Retrieved from

http://www.democraticmedia.org/us-online-data-trade-groups-spin-digital-fairy-tale-ustr-abo ut-us-consumer-privacy-prowess-cdd-say-o

Chahal, G. (2013, May). Election 2016: Marriage of big data, social data will determine the next president. Wired. Retrieved from https://www.wired.com/insights/2013/o5/election-2016marriage-of-big-data-social-data-will-determine-the-next-president/

Chavez, T. (2017, May 17). Krux is now Salesforce DMP. Salesforce Blog. Retrieved from https://www.salesforce.com/blog/2017/o5/krux-is-now-salesforce-dmp.html

Chester, J. (2007). Digital destiny: New media and the future of democracy. New York: The New Press.

Chester, J. (2017, January 6). Our next president: Also brought to you by big data and digital advertising. Moyers and Company. Retrieved from

http://billmoyers.com/story/our-next-president-also-brought-to-you-by-big-data-and-digital-a dvertising/

Clark, J. (2017, April 25). Fake news: New name, old problem. Can premium programmatic help? Advertising Age. Retrieved from

http://adage.com/article/digitalnext/fake-news-problem-premium-programmatic/308774/

Confessore, N., \& Hakim, D. (2017, March 6). Data firm says "secret sauce" aided Trump; many scoff. New York Times. Retrieved from

https://www.nytimes.com/2017/03/o6/us/politics/cambridge-analytica.html?_r=o

Crupi, A. (2015, May 27). Nielsen buys neuromarketing research company Innerscope. Advertising Age. Retrieved from http://adage.com/article/media/nielsen-buys/298771/

Delgado, M. (2016, April 28). Experian launches audience management platform to make programmatic TV a reality across advertising industry. Experian. Retrieved from http://www.experian.com/blogs/news/2016/o4/28/experian-launches-audience-managementplatform/

DoubleClick. (n.d.). DoubleClick campaign manager. Retrieved from

https://www.doubleclickbygoogle.com/solutions/digital-marketing/campaign-manager/

Drawbridge. (n.d.). Cross-device election playbook. Retrieved from

https://drawbridge.com/c/vote

Edelman Digital (2016, April 1). How digital is shaking up presidential campaigns. Retrieved from https://www.edelman.com/post/how-digital-is-shaking-up-presidential-campaigns/

Ellwanger, S. (2016, September 15). Advance Local's Sutton sees bid demand for digital advertising in politics. Retrieved from http://www.beet.tv/2016/o9/jeff-sutton.html

eMarketer. (2017, April 12). Worldwide ad spending: The eMarketer forecast for 2017.

Experian. (2015, March). Audience guide. Retrieved from

https://www.experian.com/assets/marketing-

services/product-sheets/attitudinal-and-psychographic-audiences.pdf 
Experian. (2011, December). Political affiliation and Beyond. Retrieved from https://www.experian.com/assets/marketing-services/product-sheets/daspolitical-data-sheet.pdf

Facebook. (2016, June 16). Inside marketing science at Facebook. Retrieved from https://www.facebook.com/notes/facebook-careers/inside-marketing-scienceat-facebook/936165389815348/

Facebook. (n.d.-a). Activate. Facebook Elections. Retrieved from https://politics.fb.com/adcampaigns/activate/

Facebook. (n.d.-b). Advanced strategies for performance marketers. Facebook Business. Retrieved from https://www.facebook.com/business/a/performance-marketing-strategies; https://www.facebook.com/business/help/202297959811696

Facebook. (n.d.-c). Impact. Facebook Elections. Retrieved from https://politics.fb.com/adcampaigns/impact/

Facebook. (n.d.-d). Mobilize your voters. Facebook Business. Retrieved from https://www.facebook.com/business/a/mobilizevoters

Facebook. (n.d.-e). Toomey for Senate. Facebook Business. Retrieved from https://www.facebook.com/business/success/toomey-for-senate

Facebook. (n.d.-f). Turnout. Facebook Elections. Retrieved from https://politics.fb.com/adcampaigns/turnout/

Facebook IQ. (n.d.-a). Unlock the insights that matter. Retrieved from https://www.facebook.com/iq

Facebook IQ. (n.d.-b). Vertical insights. https://www.facebook.com/iq/vertical-insights

Falck, B. (2017, October 24). New transparency for ads on Twitter. Twitter Blog.

https://blog.twitter.com/official/en_us/topics/product/2017/New-

Transparency-For-Ads-on-Twitter.html

Fourthwall Media. (n.d.). Solutions: Analytics firms. Retrieved from

http://www.fourthwallmedia.tv/analytics-firms.

Gellman, R., \& Dixon, P. (2011, October 14). Many failures: A brief history of privacy selfregulation in the United States. World Privacy Forum. Retrieved from http://www.worldprivacyforum.org/wp-content/uploads/2011/10/WPFselfregulationhistory.pd f

Glaser, A. (2017, October 17). Should political ads on Facebook include disclaimers? Slate.

Retrieved from

http://www.slate.com/articles/technology/future_tense/2017/10/the_fec_wants_your_opinio n_on_transparency_for_online_political_ads.html

Goldman, R. (2017, October 27). Update on our advertising transparency and authenticity efforts. Facebook Newsroom. Retrieved from https://newsroom.fb.com/news/2017/10/update-on-our-advertising-transparency-and-authent icity-efforts/ 
Google. (2017, May 1). Marketing in a multicultural world: 2017 Google's marketing forum. Google Agency Blog. Retrieved from https://agency.googleblog.com/2017/05/marketing-inmulticultural-world-2017.html

Google. (n.d.-a). Google NYC algorithms and optimization. Research at Google. Retrieved from https://research.google.com/teams/nycalg/

Google. (n.d.-b). Insights you want. Data you need. Think with Google. Retrieved from https://www.thinkwithgoogle.com

Green, J., \& Issenberg, S. (2016, October 27). Inside the Trump bunker, with days to go. Bloomberg Businessweek. Retrieved from https://www.bloomberg.com/news/articles/201610-27/inside-the-trump-bunker-with-12-days-to-go

Havas Cognitive. (n.d.). EagleAi has landed. Retrieved from http://cognitive.havas.com/case-studies/eagle-ai

Hoofnagle, C. (2005, March 4). Privacy self-regulation: A decade of disappointment. Electronic Privacy Information Center. Retrieved from http://epic.org/reports/decadedisappoint.html

IPA. (2017, August). IPA issues direct call to action to Google YouTube and Facebook to clean up safety, measurement and viewability of their online video. Retrieved from

http://www.ipa.co.uk/news/ipa-issues-direct-call-to-action-to-google-youtube-and-facebook-to -clean-up-safety,-measurement-and-viewability-of-their-online-video-\#.Wa126YqQzQj

IAB. (2017, October 24). IAB President \& CEO, Randall Rothenberg testifies before Congress on digital political advertising. Retrieved from https://www.iab.com/news/read-the-testimonyfrom-randall-rothenberg-president-and-ceo-iab/

IAB. (n.d.-a). The digital video advertising landscape. Retrieved from https://videoguide.iab.com/digital-video-advertising-landscape

IAB. (n.d.-b). Global digital advertising revenue reports. Retrieved from https://www.iab.com/global/

IAB. (n.d.-c). Glossary: Digital media planning \& buying. Retrieved from https://www.iab.com/wp-content/uploads/2016/o4/Glossary-Formatted.pdf

IAB. (n.d.-d). IAB internet advertising revenue report conducted by PricewaterhouseCoopers (PWC). Retrieved from https://www.iab.com/insights/iab-internet-advertising-revenuereport-conducted-by-pricewaterhousecoopers-pwc-2

Jamieson, A. (2016, April 5). The first Snapchat election: How Bernie and Hillary are targeting the youth vote. The Guardian. Retrieved from

https://www.theguardian.com/technology/2016/apr/o5/snapchat-election-2016-sanders-clint on-youth-millennial-vote

Jamieson, K. H. (1996). Packaging the presidency: A history and criticism of presidential campaign advertising. New York: Oxford University Press.

Johnson, L. (2017, April 16). How brands and agencies are fighting back against Facebook and Google's measurement snafus. Adweek. Retrieved from

http://www.adweek.com/digital/how-brands-and-agencies-are-fighting-back-against-facebook 
s-and-googles-measurement-snafus/

Karpf, D. (2017, February 1). Will the real psychometric targeters please stand up? Civicist. Retrieved from https://civichall.org/civicist/will-the-real-psychometric-targeters-pleasestand-up/

Karpf, D. (2016, October 31). Preparing for the campaign tech bullshit season. Civicist. Retrieved from https://civichall.org/civicist/preparing-campaign-tech-bullshit-season/

Kaye, K. (2015, June 3). Programmatic buying coming to the political arena in 2016. Advertising Age. Retrieved from http://adage.com/article/digital/programmatic-buying-political-arena-2016/298810/

Kaye, K. (2016, April 15). RNC'S voter data provider teams up with Google, Facebook and other ad firms. Advertising Age. Retrieved from

http://adage.com/article/campaign-trail/rnc-voter-data-provider-joins-ad-firms-including-face book/303534/

Kaye, K. (2016, July 13). Democrats' data platform opens access to smaller campaigns. Advertising Age. Retrieved from

http://adage.com/article/campaign-trail/democratic-data-platform-opens-access-smaller-cam paigns/304935/

Kelshaw, T. (2017, August). Emotion analytics: A powerful tool to augment gut instinct. Think with Google. https://www.thinkwithgoogle.com/nordics/article/emotion-analytics-apowerful-tool-to-augment-gut-instinct/

Key, W. B. (1974). Subliminal Seduction. New York: Berkeley Press.

Koltun, N. (2017, October 27). Facebook significantly ramps up transparency efforts to cover all ads. Mobile Marketer. Retrieved from https://www.mobilemarketer.com/news/facebooksignificantly-ramps-up-transparency-efforts-to-cover-all-ads/508380/

Kranish, M. (2016, October 27). Trump's plan for a comeback includes building a "psychographic" profile of every voter. The Washington Post. Retrieved from https://www.washingtonpost.com/politics/trumps-plan-for-a-comebackincludes-building-a-psychographic-profile-of-everyvoter/2016/10/27/9064a706-9611-11e6-9b7c57290af48a49_story.html?utm_term $=.28322875475 \mathrm{~d}$

Kreiss, D. (2016). Prototype politics: Technology-intensive campaigning and the data of democracy. New York: Oxford University Press.

Kreiss, D., \& Mcgregor, S.C. (2017). Technology firms shape political communication: The work of Microsoft, Facebook, Twitter, and Google with campaigns during the 2016 U.S. presidential cycle, Political Communication, 1-23. doi:10.1080/10584609.2017.1364814

L2. (n.d.-a). Digital advertising device targeting. Retrieved from

http://www.l2political.com/products/data/digital-advertising/device-targeting/

L2. (n.d.-b). L2 voter file enhancements. Retrieved from

http://www.l2political.com/products/data/voter-file-enhancements/ 
Leahey, L. (2016, July 15). (Ad) campaign season: How political advertisers are using data and digital to move the needle in 2016. Cynopsis Media. Retrieved from

http://www.cynopsis.com/cyncity/ad-campaign-season-how-political-advertisers-are-using-dat a-and-digital-to-move-the-needle-in-2016/

Letter from the guest editors: Julie Hootkin and Frank Luntz. (2016, June). Think with Google. Retrieved from https://www.thinkwithgoogle.com/marketing-resources/guest-editorspolitical-consultants-julie-hootkin-frank-luntz

Levine, B. (2016, December 2). Report: What is data onboarding, and why is it important to marketers? Martech Today. Retrieved from https://martechtoday.com/report-dataonboarding-important-marketers-19292 4

LiveRamp (2015, August 5). Look-alike modeling: The what, why, and how. LiveRamp Blog. Retrieved from http://liveramp.com/blog/look-alike-modeling-the-what-why-and-how/

Liyakasa, K. (2017, August 24). Standard media index: YouTube's direct ad spend down 26\% in Q2 amid brand safety crackdown. Ad Exchanger. Retrieved from https://adexchanger.com/adexchange-news/standard-media-index-youtubes-direct-ad-spend-26-q2-amid-brand-safetycrackdown/

Maheshwari, S., \& Isaac, M. (2016, November 6). Facebook will stop some ads from targeting users by race. New York Times Retrieved from

https://www.nytimes.com/2016/11/12/business/media/facebook-will-stop-some-ads-from-targ eting-users-by-race.html?mcubz=0

Marshall, J. (2017, January 30). IAB chief calls on online ad industry to fight fake news. Wall Street Journal. Retrieved from https://www.wsj.com/articles/iab-chief-calls-on-online-adindustry-to-fight-fake-news-1485812139

Martinez, C. (2016, October 28). Driving relevance and inclusion with multicultural marketing. Facebook Business. Retrieved from https://www.facebook.com/business/news/drivingrelevance-and-inclusion-with-multicultural-marketing

Matz, S. C., Kosinski, M., Nave, G., \& Stillwell, D. J. (2017, October 17). Proceedings of the National Academy of Sciences (PNAS Early Edition). Retrieved from

http://www.michalkosinski.com/home/publications

McCain, Klobuchar \& Warner introduce legislation to protect integrity of U.S. elections \& provide transparency of political ads on digital platforms. (2017, October 19). Retrieved from https://www.mccain.senate.gov/public/index.cfm/2017/10/mccain-klobuchar-warnerintroduce-legislation-to-protect-integrity-of-u-s-elections-provide-transparency-ofpolitical-ads-on-digital-platforms

McDermott, M. J. (2017, May 12). Brand safety issue vexes marketers. ANA Magazine. Retrieved from

http://www.ana.net/magazines/show/id/ana-2017-05-brand-safety-issue-vexes-marketers

McEleny, C. (2016, October 16). Ford and Xaxis score in Vietnam using emotional triggers around the UEFA Champions League. The Drum. Retrieved from

http://www.thedrum.com/news/2016/10/18/ford-and-xaxis-score-vietnam-using-emotional-tr iggers-around-the-uefa-champions 
Miller, S. J. (2017, March 24). Local cable and the future of campaign media strategy. Campaigns \& Elections. Retrieved from https://www.campaignsandelections.com/campaigninsider/local-cable-and-the-future-of-campaign-media-strategy

Minsker, M. (2017, August 30). Advertisers want programmatic tech players to fight fake news. eMarketer. Retrieved from https://www.emarketer.com/Article/Advertisers-WantProgrammatic-Tech-Players-Fight-Fake-News/1016406

Montgomery, K. C. (2007). Generation digital: Politics, commerce, and childhood in the age of the internet. Cambridge, MA: MIT Press.

Montgomery, K. C. (2011) Safeguards for youth in the digital marketing ecosystem. In D. G. Singer and J. L. Singer (Eds.), Handbook of children and the media (2nd ed.), pp. 631-648. Thousand Oaks, CA: Sage Publications.

Montgomery, K. C., Chester, J., \& Kopp, K. (2017). Health wearable devices in the big data era: Ensuring privacy, security, and consumer protection. Center for Digital Democracy. Retrieved from

https://www.democraticmedia.org/sites/default/files/field/public/2016/aucdd_wearablesrepo rt_final121516.pdf

Moonshadow Mobile. (n.d.). Ground Game is a groundbreaking battle-tested mobile canvassing app. Retrieved from

http://www.moonshadowmobile.com/products/ground-game-mobile-canvassing/

NCC Media. (n.d.). The essential guide to political advertising. Retrieved from

https://nccmedia.com/PoliticalEssentialGuide/html5/index.html?page=1\&noflash

Nicas, J. (2016, December 8). Fake-news sites inadvertently funded by big brands. Wall Street Journal. Retrieved from https://www.wsj.com/articles/fake-news-sites-inadvertently-fundedby-big-brands-1481193004

Nielsen. (2016, October 4). Nielsen and Ethnifacts introduce intercultural affinity segmentation to drive deeper understanding of total U.S. cultural landscape for brand marketers. Retrieved from

http://www.nielsen.com/us/en/press-room/2016/nielsen-and-ethnifacts-introduce-intercultur al-affinity-segmentation.html

Nix, A. (2016, September). The Power of Big Data and Psychographics in the Electoral Process. Presented at the Concordia Annual Summit, New York. Retrieved from

https://www.youtube.com/watch?v=n8Dd5aVXLCc

O'Hara, C. (2016, January 25). Data triangulation: How second-party data will eat the digital world. Ad Exchanger. Retrieved from

http://adexchanger.com/data-driven-thinking/data-triangulation-how-second-party-data-willeat-the-digital-world/

Owen, D. (2017). New Media and Political Campaigns. New York: Oxford University Press.

Packard, V. (2007). The Hidden Persuaders (reissue ed.). New York: Ig Publishing.

Persily, N. (2016, August 10). Facebook may soon have more power over elections than the FEC. 
Are we ready? Washington Post. Retrieved from https://www.washingtonpost.com/news/intheory/wp/2016/o8/10/facebook-may-soon-have-more-power-over-elections-than-the-fecare-we-ready/?utm_term=.ed1oeef711a1

Political campaigns in 2016: The climax of digital advertising. (2016, May 10). Media Radar. Retrieved from

https://www.slideshare.net/JesseSherb/mediaradarwhitepaperdigitalpoliticalfinpdf

Regan, J. (2016, July 29). Donkeys, elephants, and DMPs. Merkle. Retrieved from https://www.merkleinc.com/blog/donkeys-elephants-and-dmps

Regan, T. (2016, January). Media planning toolkit: Programmatic planning. WARC. Retrieved from

https://www.warc.com/content/article/bestprac/media_planning_toolkit_programmatic_plan $\operatorname{ning} / 106391$

Revolution Messaging. (n.d.). Smart cookies. Retrieved from

https://revolutionmessaging.com/marketing/smart-cookies.

Rubinstein, I. S. (2014) Voter privacy in the age of big data. Wisconsin Law Review. Retrieved from

http://wisconsinlawreview.org/wp-content/uploads/2015/o2/1-Rubinstein-Final-Online.pdf

Sabato, L. J. (1981). The rise of political consultants: New ways of winning elections. New York: Basic Books.

Salesforce DMP. (2017, October 20). Third-party data marketplace. Retrieved from https://konsole.zendesk.com/hc/en-us/articles/217592967-Third-Party-Data-Marketplace

Schiller, H. I. (2007). The Mind Managers. New York: Beacon Press.

Schuster, J. (2015, October 7) Political campaigns: The art and science of reaching voters. LiveRamp. Retrieved from https://liveramp.com/blog/political-campaigns-the-art-andscience-of-reaching-voters/

Schwartz, M. (2017, March 30). Facebook failed to protect 30 million users from having their data harvested by Trump campaign affiliate. The Intercept. Retrieved from https://theintercept.com/2017/03/30/facebook-failed-to-protect-30million-users-from-having-their-data-harvested-by-trump-campaign-affiliate/

Schwartz, P. M., \& Solove, D. J. (2011). The PII problem: Privacy and a new concept of personally identifiable information. New York University Law Review, 86, 1814-1895. Retrieved from https://papers.ssrn.com/sol3/papers.cfm?abstract_id=1909366

Singer, N. (2012, October 13). Do not track? Advertisers say “don’t tread on us.” New York Times. Retrieved from

http://www.nytimes.com/2012/10/14/technology/do-not-track-movement-is-drawing-advertis ers-fire.html?_r=o

Smith, C. (2014, March 20). Reinventing social media: Deep learning, predictive marketing, and image recognition will change everything. Business Insider. Retrieved from

http://www.businessinsider.com/social-medias-big-data-future-2014-3 
Solon, O., \& Siddiqui, S. (2017, September 3). Forget Wall Street-Silicon Valley is the new political power in Washington. The Guardian. Retrieved from https://www.theguardian.com/technology/2017/sep/o3/silicon-valley-politics-lobbying-washi ngton

Solove, D. J., \& Hartzog, W. (2014). The FTC and the new common law of privacy. Columbia Law Review, 114, 583-677. Retrieved from https://papers.ssrn.com/sol3/papers.cfm?abstract_id=2312913

Son, S., Kim, D., \& Shmatikov, V. (2016). What mobile ads know about mobile users. NDSS '16. Retrieved from http://www.cs.cornell.edu/ shmat/shmat_ndss16.pdf

Stanford, K. (2016, March). How political ads and video content influence voter opinion. Think with Google. Retrieved from https://www.thinkwithgoogle.com/marketing-resources/contentmarketing/political-ads-video-content-influence-voter-opinion/

Stirista. (n.d.). Political data. Retrieved from https://www.stirista.com/what-wedo/data/political-data

Timmers, B. (2015, December). Everything you wanted to know about fake news. IAS Insider Retrieved from https://insider.integralads.com/everything-wanted-know-fake-news/

Tufecki, Z. (2014, July 7). Engineering the public: Big data, surveillance and computational politics. First Monday 19(7). Retrieved from http://firstmonday.org/article/view/4901/4097

U.S. Senate Committee on Commerce, Science, and Transportation. (2013, December 18). A review of the data broker industry: Collection, use, and sale of consumer data for marketing purposes. Staff report for Chairman Rockefeller. Retrieved from https://www.commerce.senate.gov/public/_cache/files/od2b3642-6221-4888-a631-o8f2f255b 577/AE5D72CBE7F44F5BFC846BECE22C875B.12.18.13-senate-commerce-committeereport-on-data-broker-industry.pdf

Vranica, S. (2017, June 18). Advertisers try to avoid the web's dark side, from fake news to extremist videos. Wall Street Journal. Retrieved from

https://www.wsj.com/articles/advertisers-try-toavoid-the-webs-dark-side-from-fake-news-to-extremist-videos-1497778201

WARC. (2017, December). Toolkit 2018: How brands can respond to the year's biggest challenges. Retrieved from

https://www.warc.com/content/article/Toolkit_2018_How_brands_can_respond_to_the_yea ramp;39;s_biggest_challenges/117399

Warrington, G. (2015, November 18). Tiles, proxies and exact places: Building location audience profiles. LinkedIn. Retrieved from https://www.linkedin.com/pulse/tiles-proxies-exact-placesbuilding-location-audience-warrington

Weissbrot, A. (2016, June 20). MAGNA and Zenith: Digital growth fueled by programmatic, mobile and video. Ad Exchanger. Retrieved from https://adexchanger.com/agencies/magnazenith-digital-growth-fueled-programmatic-mobile-video/

What is predictive intelligence and how it's set to change marketing in 2016. (2016, February 11). Smart Insights. 
http://www.smartinsights.com/digital-marketing-strategy/predictive-intelligence-set-changemarketing-2016/

Winterberry Group. (2016, November). The state of consumer data onboarding: Identity resolution in an omnichannel environment. Retrieved from

http://www.winterberrygroup.com/our-insights/state-consumer-data-onboarding-identity-reso lution-omnichannel-environment

Xaxis. (2015, November 9). Xaxis brings programmatic to political advertising with Xaxis politics, first ad targeting solution to leverage offline voter data for reaching U.S. voters across all digital channels. https://www.businesswire.com/news/home/20151109006051/en/XaxisBrings-Programmatic-Political-Advertising-Xaxis-Politics

Yatrakis, C. (2016, June 28). The Trade Desk partner spotlight: Q\&A with Factual. Factual. Retrieved from https://www.factual.com/blog/partner-spotlight

YouTube. (2017). The presidential elections on YouTube. Retrieved from https://think.storage.googleapis.com/docs/The_Presidential_Elections_On_YouTube.pdf

\section{FOOTNOTES}

1. The research for this paper is based on industry reports, trade publications, and policy documents, as well as review of relevant scholarly and legal literature. The authors thank Gary O. Larson and Arthur Soto-Vasquez for their research and editorial assistance. 